\title{
Variation in the Age at Menarche of the Assamese and Bengali Girls of Guwahati, Assam
}

\author{
Roumi Deb \\ Amity Institute of Biotechnology, Amity University,Uttar Pradesh, Sector-125, Noida, \\ Uttar Pradesh, India
}

KEYWORDS: Kayastha, Socio-economic, Environmental, Multifactorial, Guwahati

\begin{abstract}
Data on age at menarche have been collected using status quo method among 230 Assamese girls and 223 Bengali girls of Guwahati (Assam) attending School. The median age, estimated by probits, is $12.45 \pm 0.02$ year among Assamese girls and $12.25 \pm 0.03$ year among the Bengali girls, respectively. However the difference $(\mathrm{t}=6.49)$ is found to be statistically significant $(\mathrm{P}<0.01)$. Age at menarche in relation with food habit, housing facilities and games were taken into consideration. However, the interpretation of these associations cannot be recognized as a cause and effect relationship, since these are secondary factors that are more or less associated with those factors that presumably have a more direct influence, such as nutritional status and health status etc.
\end{abstract}

\section{INTRODUCTION}

Age at menarche is an important indicator of physiological development in female and, consequently, it has been extensively studied in many populations as well as many ethnic groups (Eveleth and Tanner 1976). Average age at menarche finds application in a variety of contexts. It is an excellent overall comparative indicator of population health, timing of maturation and nutritional status (Tanner and Eveleth 1975). Average age at menarche is also widely used as demographic indicator of population fecundity (Urdy and Cliquet 1982)

Age at menarche occurs earlier than it once did in many parts of the world, especially in Europe and North America (Eveleth 1986; Laslett 1985; Tanner 1973; Wyshak and Frisch 1982). In these regions, age at menarche declined at the rate of $\sim 0.3$ y per decade till it stabilized at $\sim 13$ y (Eveleth 1986; Poppleton and Brown 1966; Sandler et al. 1984; Tanner 1981). This decline, also seen in some developing countries, has been attributed to improvements in nutrition and health (Bielicki et al. 1986; Eveleth 1986; Hulanicka and Waliszko 1991; Laslett 1985; Low et al. 1982; Malina et al. 1977; Rona 1975; Singh and Malhotra 1988). Similarly, the fact that menarche occurs later in the poorer social classes compared with the well to-do in developing countries has been ascribed to disparities in nutrition and health (Charzewska et al. 1976; Chowdhury et al. 1977; Eveleth and Tanner 1990; Foster et al.1986; Gandotra and Das 1982; Rana et al. 1986; Tan-Boom et al.1983; Uche and Okorafor 1979).
Different environmental factors besides heredity are associated with the variation in mean age at menarche. Effects of climate, altitude, rural and urban residence, socio-economic level of family, family size, dietary habit, nutrition, birth order, general health consideration, some chronic diseases are considered to be the cause of variation in menarcheal age by different researches (Tanner 1962).

Improvements in the quality of life during early childhood can result in earlier menarche. Indian and Bangladeshi girls adopted between 1 month and 11 years of age (mean age $3.7 \mathrm{y}$ ) by Swedish families experienced earlier pubertal growth and menarche compared with Swedish and affluent Indian girls (Adolfsson and Westphal 1981; Proos et al. $1991 \mathrm{a}, \mathrm{b}$ ).

In Assam, Rakshit (1960), Das and Das (1967) Deka (1976), Srivastava and Goswami (1968) and Das (1986) have studied population variations in mean age at menarche. In the present study of the Assamese and Bengali girls of Guwahati, an attempt has been made to study age at menarche with food habits, housing facilities and games.

\section{MATERIAL AND METHODS}

The data consist of 453 subjects, which comprises of 223 Bengali girls and 230 Assamese girls in age from 10-16 years. The study was conducted in Guwahati, capital of Assam and is situated in the north-eastern part of India. Menarche data were gathered during 1992; each subject was asked whether they had reached menarche. Those who answered affirmatively 
were then asked to recall the year and month of occurrence. All interviews were conducted at home.

These girls are born and brought up in Guwahati, and are derived from different High and Higher Secondary Schools located in the city. The date of birth of each subject was recorded from the admission registers maintained by respective schools. The data of birth was converted in to decimal age following the decimal calendar given by Tanner et al. (1969).

All the subjects belong to the caste 'Kayastha'. Basic background information was taken on each subject including date and place of birth, class and school in which she is studying and total family income per month. Additional relevant information such as food habits and living conditions was gathered from each subject.

Age at menarche of each girl was obtained by 'status-quo' method; with this method it is possible to collect menarche data for large representative samples of girls within a comparatively short period, where only the age of girls and the information whether the menstruation has already occurred is collected. The data thus collected are subjected to analysis by probits according, to Tanner (1966) and Cameron et al. (1981).

\section{RESULTS}

In the present study, each girl was asked as to whether menarche has occurred or not. Their age was converted to decimal age and the percentage of those reporting in the affirmative was calculated.

Table 1, gives the number and percentage of girls in whom menarche has occurred. It is observed that at 10 years no girls of both Assamese and Bengali girls had experience menarche. Only one Bengali girl belonging to age group 11 years had reported the occurrence of menarche; whereas, more of the Assamese girls belonging to this age group reported the occurrence of menarche. In the age group of 12 years, approximately $25.81 \%$ of Assamese girls reported menarche to have occurred. On the contrary, in about $45.16 \%$ Bengali girls aged 12 years menarche has occurred. Similarly, for age group 13 years about $74.42 \%$ Assamese girls and $82.12 \%$ Bengali girls reported menarche. It is observed that cent percent girls belonging to age group 14, 15, and 16 years of both the ethnic groups reported menarche to have already occurred. Considering all the age group together

Table 1: Age group wise frequency and percentage of girls reporting the occurrence of menarche.

\begin{tabular}{lrrr}
\hline $\begin{array}{l}\text { Age group } \\
\text { (years) }\end{array}$ & $N$ & $\begin{array}{c}\text { Menarche } \\
\text { occurred } \\
F(\%)\end{array}$ & $\begin{array}{r}\text { Menarche } \\
\text { noccurred } \\
F(\%)\end{array}$ \\
\hline Assamese & & & \\
10 & 31 & $0(00.00)$ & $31(100.00)$ \\
11 & 32 & $0(00.00)$ & $32(100.00)$ \\
12 & 31 & $8(25.81)$ & $23(74.19)$ \\
13 & 29 & $21(72.42)$ & $8(27.58)$ \\
14 & 43 & $43(100.00)$ & $0(00.00)$ \\
15 & 26 & $26(100.00)$ & $0(00.00)$ \\
16 & 38 & $38(100.00)$ & $0(00.00)$ \\
Total & & $136(59.13)$ & $94(40.87)$ \\
Bengali & 32 & & \\
10 & 32 & $1(00.00)$ & $32(100.00)$ \\
11 & 31 & $14(45.13)$ & $31(96.87)$ \\
12 & 34 & $30(88.21)$ & $4(54.84)$ \\
13 & 31 & $31(100.00)$ & $0(00.00)$ \\
14 & 32 & $32(100.00)$ & $0(00.00)$ \\
15 & 31 & $31(100.00)$ & $0(00.00)$ \\
16 & & $139(62.33)$ & $84(37.67)$ \\
Total & & & \\
\hline
\end{tabular}

Table 2: Frequency and percentage of girls having different food habits, etc., according to Menarche status.

\begin{tabular}{|c|c|c|c|c|c|c|}
\hline \multirow[t]{2}{*}{ Menarcheal status } & \multicolumn{4}{|c|}{ Food habits } & \multicolumn{2}{|c|}{ Games } \\
\hline & Vegetarian & $\begin{array}{c}\text { Non- } \\
\text { vegetarian }\end{array}$ & $\begin{array}{l}\text { Drinking } \\
\text { milk (Yes) }\end{array}$ & $\begin{array}{c}\text { Drinking } \\
\text { milk }(N o)\end{array}$ & $\begin{array}{l}\text { Partici- } \\
\text { pating }\end{array}$ & $\begin{array}{c}\text { Not } \\
\text { participating }\end{array}$ \\
\hline \multicolumn{7}{|l|}{ Assamese } \\
\hline MenarcheOccurred $(\mathrm{N}=136)$ & 1 & 135 & 81 & 55 & 86 & 50 \\
\hline Occurred $(N=136)$ & $(0.73)$ & $(99.26)$ & $(59.55)$ & $(40.44)$ & $(63.23)$ & $(36.76)$ \\
\hline \multirow[t]{2}{*}{ Menarche Not Occurred $(\mathrm{N}=94)$} & 0 & 94 & 81 & 13 & 75 & 19 \\
\hline & $(0.00)$ & $(100.00)$ & $(86.17)$ & $(13.83)$ & $(79.79)$ & $(20.21)$ \\
\hline \multicolumn{7}{|l|}{ Bengali } \\
\hline \multirow[t]{2}{*}{ Menarche Occurred $(\mathrm{N}=139)$} & 2 & 137 & 90 & 46 & 77 & 63 \\
\hline & $(1.44)$ & $(98.56)$ & $(66.91)$ & $(33.09)$ & $(55.39)$ & $(45.32)$ \\
\hline \multirow[t]{2}{*}{ Menarche Not Occurred $(\mathrm{N}=84)$} & ) 0 & 84 & 74 & 10 & 77 & 7 \\
\hline & $(0.00)$ & $(100.00)$ & (88.09) & (11.9) & $(91.66)$ & (8.33) \\
\hline
\end{tabular}


in $136(59.13 \%)$ out of total 230 Assamese girls and $139(62.33 \%)$ of 223 Bengali girls of the present study reported the occurrence of menarche.

In order to calculate the media age at menarche the percentage value were converted to probit values, a graphic location of median age thus derived in 12.45 years of Assamese girls with SD 0.02 and 12.25 years for Bengali girls with SD 0.03 . However, the difference $(\mathrm{t}=6.49)$ is found to be statistically significant $(\mathrm{p}<0.01)$

\section{Environmental Factors and Menarche}

The data on Assamese and Bengali girls was segregated into two components: (i) in whom menarche had occurred, (ii) in whom menarche had not occurred.

Almost all Assamese as well as Bengali girls of our sample are non-vegetarian. Among those girls in whom menarche had occurred at the time of investigation, only one Assamese while two Bengali girls reported to be strictly vegetarian. On the other hand, both Assamese and Bengali girls in who menarche had not occurred none was found to be vegetarian. Based on the distribution given in the table 2, on statistically significant association (Assamese chi-square $=0.69$, Bengali chi-square $=1.21$ ) is observed between vegetarian/ non-vegetarian food habits and occurrence of menarche. Under the second category of food habits the girls who are asked whether they drink milk regularly or not. It can be seen from the table that a slightly greater percentage of Bengali girls consume milk regularly as compared Assamese girls. On the other hand, 59 to 88 per cent of the girls in the two samples reported daily consumption of milk, whether they have experienced menarche or not. The frequency distribution of milk drinking habits vis-à-vis menarcheal status gives statistically significant results for Assamese (chi-square $=14.48, \mathrm{P}<0.00$ ) and Bengali (chi-square $=10.18, \mathrm{P}<0.01$ ) girls.

Participation in games and sport gives enough opportunity for outside exposure to the girls thereby providing them probably some kind of psychosocial stimulation in addition to physical exercise. In the present study a greater percentage of girls reported as playing one or the other outdoor games. The frequency distribution of participation/non- participation in games vis-avis menarcheal status is given in the table reveals statistically significant values for chi-square in the two populations considered in the present study (Assamese, chi-square $=7.25, \mathrm{P}<0.01$; Bengali, chi-square $=32.81, \mathrm{P}<0.01$ ) (See Table 2).

In addition to biological factors such as nutrition and food habits and physical exercise some social and psychosocial factors are known to be associated with onset of menarche (Table 3 ). In the present study the housing condition facilities of the subjects were investigated. All the Assamese girls of our samples were residing in the known middle class locations. More than $50 \%$ of the subjects (both Assamese and Bengali) of our study are living in rented accommodation. In both Assamese and Bengali populations a greater percentage of girls in whom menarche has occurred are staying in the houses owned by their families as compared to those in whom menarche has not occurred. The type of accommodation and occurrence of menarche reveals statistically significant difference only for the Bengali samples of our study (chi-square $=6.46, \mathrm{P}<0.05$ ). A very

Table 3: Frequency and percentage of girls having different housing facilities etc., according to menarcheal status.

\begin{tabular}{|c|c|c|c|c|c|c|c|c|c|}
\hline \multirow[t]{3}{*}{ Menarcheal status } & \multicolumn{9}{|c|}{ Housing facilities } \\
\hline & \multicolumn{3}{|c|}{ Locality } & \multicolumn{2}{|c|}{ House } & \multicolumn{2}{|c|}{ Bathroom } & \multicolumn{2}{|c|}{ Sleeping room } \\
\hline & Slum & $\begin{array}{l}\text { Middle } \\
\text { class }\end{array}$ & Posh & Own & Rented & $\begin{array}{l}\text { Indepen- } \\
\text { dent }\end{array}$ & Shared & $\begin{array}{l}\text { Indepen- } \\
\text { dent }\end{array}$ & Shared \\
\hline \multicolumn{10}{|l|}{ Assamese } \\
\hline $\begin{array}{l}\text { Menarche Occurred } \\
(\mathrm{N}=136)\end{array}$ & $\begin{array}{c}0 \\
(0.00)\end{array}$ & $\begin{array}{c}136 \\
(100.00)\end{array}$ & $\begin{array}{c}0 \\
(0.00)\end{array}$ & $\begin{array}{c}43 \\
(31.36)\end{array}$ & $\begin{array}{c}93 \\
(68.38)\end{array}$ & $\begin{array}{c}131 \\
(96.38)\end{array}$ & $\begin{array}{c}5 \\
(3.68)\end{array}$ & $\begin{array}{c}31 \\
(22.79)\end{array}$ & $\begin{array}{c}105 \\
(77.20)\end{array}$ \\
\hline $\begin{array}{l}\text { Menarche Not Occurred } \\
(\mathrm{N}=94)\end{array}$ & $(0.00)$ & $\begin{array}{c}94 \\
(100.00)\end{array}$ & $\begin{array}{c}0 \\
(0.00)\end{array}$ & $\begin{array}{c}20 \\
(21.28)\end{array}$ & $\begin{array}{c}74 \\
(78.72)\end{array}$ & $\begin{array}{c}90 \\
(95.74)\end{array}$ & $\begin{array}{c}4 \\
(4.25)\end{array}$ & $\begin{array}{c}4 \\
(4.25)\end{array}$ & $\begin{array}{c}90 \\
(95.74)\end{array}$ \\
\hline \multicolumn{10}{|l|}{ Bengali } \\
\hline $\begin{array}{l}\text { Menarche Occurred } \\
(\mathrm{N}=139)\end{array}$ & $\begin{array}{c}0 \\
(0.00)\end{array}$ & $\begin{array}{c}132 \\
(94.96)\end{array}$ & $\begin{array}{c}7 \\
(5.04)\end{array}$ & $\begin{array}{c}65 \\
(46.36)\end{array}$ & $\begin{array}{c}74 \\
(53.24)\end{array}$ & $\begin{array}{c}126 \\
(90.65)\end{array}$ & $\begin{array}{c}13 \\
(9.35)\end{array}$ & $\begin{array}{c}20 \\
(14.39)\end{array}$ & $\begin{array}{c}119 \\
(85.61)\end{array}$ \\
\hline $\begin{array}{l}\text { Menarche Not Occurred } \\
(\mathrm{N}=84)\end{array}$ & $(1.19)$ & $\begin{array}{c}81 \\
(96.43)\end{array}$ & $\begin{array}{c}2 \\
(2.38)\end{array}$ & $\begin{array}{c}30 \\
(35.71)\end{array}$ & $\begin{array}{c}54 \\
(64.28)\end{array}$ & $\begin{array}{c}80 \\
(95.24)\end{array}$ & $\begin{array}{c}4 \\
(4.76)\end{array}$ & $\begin{array}{c}11 \\
(13.09)\end{array}$ & $\begin{array}{c}73 \\
(86.90)\end{array}$ \\
\hline
\end{tabular}


Table 4: Percentage of girls having different number of brothers and sisters according to menarcheal status

\begin{tabular}{|c|c|c|c|c|c|c|c|c|c|}
\hline \multirow[t]{2}{*}{ Menarcheal status } & \multicolumn{9}{|c|}{ Number of brothers and Sisters (excluding the subject) } \\
\hline & 1 & 2 & 3 & 4 & 5 & 6 & 7 & 8 & 9 \\
\hline \multicolumn{10}{|l|}{ Assamese } \\
\hline $\begin{array}{l}\text { Menarche Occurred } \\
(\mathrm{N}=136)\end{array}$ & $\begin{array}{c}6 \\
(85.71)\end{array}$ & $\begin{array}{c}26 \\
(59.09)\end{array}$ & $\begin{array}{c}49 \\
(52.13)\end{array}$ & $\begin{array}{c}31 \\
(56.36)\end{array}$ & $\begin{array}{c}15 \\
(78.95)\end{array}$ & $\begin{array}{c}8 \\
(80.00)\end{array}$ & $\begin{array}{c}1 \\
(100.00)\end{array}$ & & \\
\hline $\begin{array}{l}\text { Menarche Not Occurred } \\
(\mathrm{N}=94)\end{array}$ & $\begin{array}{c}1 \\
(14.29)\end{array}$ & $\begin{array}{c}18 \\
(40.91)\end{array}$ & $\begin{array}{c}45 \\
(47.87)\end{array}$ & $\begin{array}{c}24 \\
(43.64)\end{array}$ & $\begin{array}{c}4 \\
(21.05)\end{array}$ & $\begin{array}{c}2 \\
(20.00)\end{array}$ & $\begin{array}{c}0 \\
(0.00)\end{array}$ & & \\
\hline \multicolumn{10}{|c|}{ 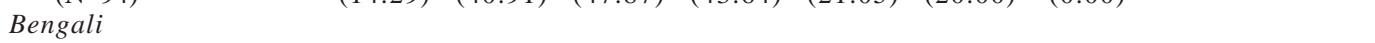 } \\
\hline $\begin{array}{l}\text { Menarche Occurred } \\
(\mathrm{N}=139)\end{array}$ & $\begin{array}{c}5 \\
(38.46)\end{array}$ & $\begin{array}{c}26 \\
(41.94)\end{array}$ & $\begin{array}{c}49 \\
(65.33)\end{array}$ & $\begin{array}{c}31 \\
(75.61)\end{array}$ & $\begin{array}{c}0 \\
(100.00)\end{array}$ & $\begin{array}{c}6 \\
(75.00)\end{array}$ & $\begin{array}{c}6 \\
6(75.00)\end{array}$ & $\begin{array}{c}1 \\
(50.00)\end{array}$ & $\begin{array}{c}3 \\
(100.00)\end{array}$ \\
\hline $\begin{array}{l}\text { Menarche Not Occurred } \\
(\mathrm{N}=84)\end{array}$ & $\begin{array}{c}8 \\
(61.54)\end{array}$ & $\begin{array}{c}36 \\
(58.06)\end{array}$ & $\begin{array}{c}26 \\
(64.67)\end{array}$ & $\begin{array}{c}10 \\
(24.39)\end{array}$ & $\begin{array}{c}0 \\
(0.00)\end{array}$ & $\begin{array}{c}2 \\
(25.00)\end{array}$ & $\begin{array}{c}2 \\
(25.00)\end{array}$ & $\begin{array}{c}1 \\
(50.00)\end{array}$ & $\begin{array}{c}0 \\
(0.00)\end{array}$ \\
\hline
\end{tabular}

low percentage girls belonging to both, Assamese and Bengali, samples share their bathrooms or enjoy the facility of exclusively independent bedrooms. However, only in the case of Assamese girls a significant chi-square value (chi-square $=14.75, \mathrm{P}<0.01$ ) is observed between independent /shared bathroom and menarcheal status.

Many studies have been reported on the association of small and large families with early and late onset of menarche, respectively. Table-4 gives the percentage of girls having different number of brothers and sisters (excluding the subject) according to menarcheal status in the two population groups. In the Assamese population of the present study a greater percentage of girls having two, three or more brothers and sisters reported the occurrence as compared to those in whom menarche had not occurred. A similar situation is observed among Bengali girls, except in those girls who had one or two co-borns where a comparatively lesser percentage of girls reported the occurrence of first menstruation.

\section{DISCUSSION}

Of all the developmental milestones associated with the adolescent years, menarche, among girls is the most noteworthy. Many interrelated factors may influence menarchial age. These factors are socio-economic status (nutrition, health, family size, living conditions), geographic environment (temperature, altitude, humidity and seasonal rhythm), and genetic influences (race/ethnic group, family heredity, constitutional type). A change in some of these factors is known to cause an increase or decrease in the onset of menarche.

While some individuals may reject the notion that the maturation process precedes as a unit
(Brown 1966), others have pointed out many associations among measures of maturation (Tanner 1962), so that the age at menarche does become a very useful parameter. Among samples of populations from around the world, a striking range of variation exists in the mean ages at menarche reported in the literature. Given a discrete event that shows such sensitivity to appropriate determinations, and such strong associations with other events, it is no wonder that innumerable studies have appeared on the subject. However, in view of the wide variation in ages at menarche, and the correlation of these ages with, so many factors, truly analytical studies require a fair amount of sophistication in design in order to disentangle these factors.

The evaluation of environmental control and their associations with the age of menarche is exceedingly complex. Part of the complexity rests with the variety of extrinsic phenomena, which are associated with accelerated or delayed ages at menarche. And part is due to the frequent inability to identify the relevant environmental factors from a statistically significant co-relation. One needs to verify whether the association represents the activity of yet another variable, or whether there is any cost and effect element involve.

Degree of urbanization, occupation and educational status of parents, family income, dwelling conditions, as well as family size do not exert a direct influence on the occurrence of the first menstruation (Danker-Hopfe 1986). These are essentially 'secondary' factors, which are more or less associated with those factors that presumably have a more direct influence, such as nutritional condition and health status. The significance of psychosocial stimuli and physical activity for maturation process is difficult to 
evaluate (Malina 1983). The strength of the relationship between the 'primary' factors and those, which are used to define social strata probably, varies from population to population and place to place, and this influences the results. Several studies have indicated that 'secondary' factors which is univariate analysis are apparently associated with the age at menarche, lose their significance when a multivariate design is used, i.e, their apparent influence is mediated through another correlated variable (Roberts and Dann 1967).

With so many associations, it has proved to be exceedingly difficult to sort out, in any meaningful fashion, the interactions between the various associations as well as the reduction to reduce the common denominators (Johnston et al. 1975). There is, thus a need for study on a large representative samples that include many variables which are known to influence menarche and studies that utilize multivariate models. Such comprehensive multifactorial studies should be expected to provide further insight into explaining variation in age at menarche.

\section{REFERENCES}

Adolfsson S, Westphal O 1981. Early pubertal development in girls adopted from Far-eastern countries. Pediatr Res, 15: 82 (abs.).

Bielicki T, Waliszko A, Hulanicka B, Kotlarz K 1986. Social-class gradients in menarcheal age in Poland. Ann Hum Biol, 13: 1-11.

Brown PE 1966. The age at Menarche. Brit Ll'rev Soc Med, 209-214.

Cameron N, Hiemaux J, Jarman S and Tanner JM 1981. Puberty Rating. In: LS Lourie (Eds): Practical Human Biology. London: Academic Press

Charzewska J, Ziemlanski S, Lasecka E 1976. Menarcheal age, nutrition and socioeconomic environment. Stud Phys Anthropol, 2: 47-51

Chowdbury AKMA, Huffman SL, Curlin GT 1977. Malnutrition, menarche and marriage in rural Bangladesh. Soc Biol, 24: 316-325.

Danker-Hopfe H 1986. Menarcheal age in Europe. Yearbook of physical Anthropology, 29: 81-112.

Deka R 1976. Age at Menarche and Haemoglobin E among the Kachari women of Upper Assam. Man in India, 56(4): 349-354.

Das PB, Das BM 1967. Age at Menarche of Kalita girls in Assam. Man in India, 47(2): 113-117.

Eveleth PB, Tanner JM 1976. Worldwide Variation in Human Growth. Cambridge: Cambridge. University Press.

Eveleth PB 1986. Timing of menarche: secular trend and population differences. In: JB Lancaster, BA Hamburg (Eds.): School-Age Pregnancy and Parenthood: Biosocial Dimensions Aldine de Gruyter, pp. 39-52.
Foster A, Menken J, Chowdhury A, Trussell J 1986. Female reproductive development: a hazard model analysis. Soc Biol, 33: 183-198.

Gandotra MM, Das N 1982. Age at menarche in an Indian population. Health Educ, 5: 168-181.

Hulanicka B, Waliszko A 1991. Deceleration of age at menarche in Poland. Ann Hum Biol, 18: 507-513.

Johnston FE 1975. Control of age at Menarche. Human Biology, 3: 279-282.

Laslett P 1985. Age at menarche in Europe since the eighteenth century. J Interdiscip Hist, 16: 221-236.

Low WD, Kung LS, Leong CY 1982. Secular trend in the sexual maturation of Chinese girls. Hums Biol, 54: 539-551.

Malina RM, Chumlea C, Dutton-Stepick S, GutierrezLopez F 1977. Age of menarche in Oaxaca, Mexico schoolgirls with comparative data for other areas of Mexico. Ann Hum Biol, 4: 551-558.

Malina RM 1983. Menarche in Athletes: A Synthesis and hypothesis. Annals in Human Biology, 10: 1-24.

Poppleton PK, Brown PE 1966. The secular trend in puberty: has stability been achieved. $B r J E d u c$ Psychol, 36: 95-100.

Proos LA, Hofvander Y, Tuvemo T 1991a. Menarcheal age and growth pattern of Indian girls adopted in Sweden. Acta Paediatr Scand, 80: 852-858.

Proos LA, Hofvander Y, Tuvemo T 1991b. Menarcheal age and growth pattern of Indian girls adopted in Sweden. II. Catch-up growth and final height. Indian J Pediatr, 58: 105-114.

Rakshit S 1960. A Short Note on the Menarcheal Age of Assamese girls. Man in India, 40(1-2): 50-55.

Rana T, Raman L, Rau P, Rao KVTI 1986. Association of growth status and age at menarche in urban upper middle income group girls of Hyderabad. Indian $J$ Med Res, 84: 522-530.

Roberts DF, Dann TE 1967. Influence of Menarcheal age in a Welsh College. Brit J Prev Soc Med, 21: 170-176.

Rona R 1975. Secular trend of pubertal development in Chile. J Hum Evol, 4: 251-257.

Sandler DP, Wilcox AJ, Homey LF 1984. Age at menarche and subsequent reproductive events. Am J Epidemiol, 119: 765-774.

Singh SP, Malhotra PI 1988. Secular shift in menarcheal age of Patiala (India) schoolgirls between 1974 and 1986. Ann Hum Biol, 15: 77-80.

Srivastava RP, Goswami M 1968. Menarcheal Age of Assamese girls. Anthropologists, 15(1-2): 57-60.

Tanner IM, Eveleth PB 1975. Variability between population in growth and Development at puberty. In: SR Berenberg (Ed): puberty, Biologic and Psychological Componenls, Leiden: Stenfert Krosese Publishers, pp. 256-273.

Tan-Boom A, Othman R, Butz WP, DaVanzo J 1983. Age at menarche in Peninsular Malaysia: time trend, ethnic differentials, and association with ages at marriages and at first birth. J Reprod Health, 1: 91108.

Tanner JM 1962. Growth at Adolescence. Oxford: Blackwell Scientific Publication.

Tanner JM 1966. The secular trend towards earlier physical maturation. T Soc Geneesk, 44: 524-539.

Tanner JM 1973. Trend towards earlier menarche in 
London Oslo, Copenhagen, The Netherlands, and Hungary. Nature (London), 243: 95-96.

Uche GO, Okorafor AE 1979. The age of menarche in Nigerian urban school girls. Ann Hum Biol, 6: 395398.
Urdy JR, Cliquet RI 1982. Cross- Cultural examination of relationship between age at menarche, marriage and first birth. Demography, 19: 53-63.

Wyshak G, Frisch RE 1982. Evidence for a secular trend in the age of menarche. N Engl J Med, 305: 10331035 . 